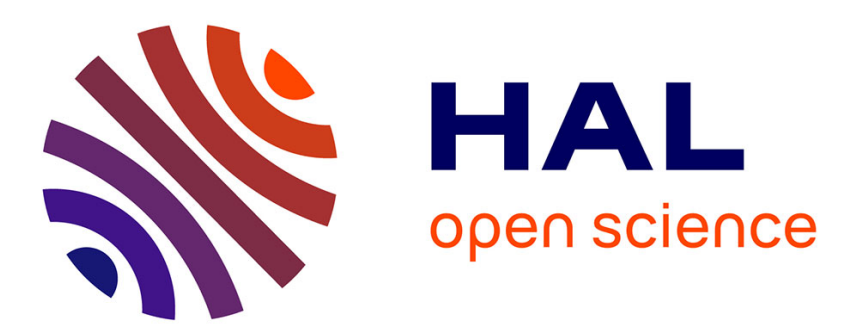

\title{
Molecular dynamics simulation of energetic uranium recoil damage in zircon
}

\author{
R. Devanathan, L. R Corrales, W. J. Weber, A. Chartier, C. Meis
}

\section{To cite this version:}

R. Devanathan, L. R Corrales, W. J. Weber, A. Chartier, C. Meis. Molecular dynamics simulation of energetic uranium recoil damage in zircon. Molecular Simulation, 2006, 32 (12-13), pp.1069-1077. $10.1080 / 08927020600959929$. cea-02513503

\section{HAL Id: cea-02513503 https://hal-cea.archives-ouvertes.fr/cea-02513503}

Submitted on 20 Mar 2020

HAL is a multi-disciplinary open access archive for the deposit and dissemination of scientific research documents, whether they are published or not. The documents may come from teaching and research institutions in France or abroad, or from public or private research centers.
L'archive ouverte pluridisciplinaire HAL, est destinée au dépôt et à la diffusion de documents scientifiques de niveau recherche, publiés ou non, émanant des établissements d'enseignement et de recherche français ou étrangers, des laboratoires publics ou privés. 


\section{Molecular dynamics simulation of energetic uranium recoil damage in zircon}

\section{R. DEVANATHAN*†, L. R. CORRALES $\dagger$, W. J. WEBER $\dagger$, A. CHARTIER $\$$ AND C. MEIS $\$$}

$\dagger$ Fundamental Science Directorate, Pacific Northwest National Laboratory, Richland, WA 99352, USA

\$CEA Center d’Etudes de Saclay, 91191 Gif-Sur-Yvette, France

Defect production and amorphization due to energetic uranium recoils in zircon $\left(\mathrm{ZrSiO}_{4}\right)$, which is a promising ceramic nuclear waste form, is studied using molecular dynamics simulations with a partial charge model. An algorithm that distinguishes between undamaged crystal, crystalline defects and amorphous regions is used to develop a fundamental understanding of the primary damage state. The damage consists of under-coordinated $\mathrm{Zr}$ and polymerised Si leading to amorphization and phase separation on a nanometer scale into $\mathrm{Zr}$ - and Si-rich regions. This separation could play an important role in the experimentally observed formation of nanoscale $\mathrm{ZrO}_{2}$ in $\mathrm{ZrSiO}_{4}$ irradiated at elevated temperatures. The observed amorphisation and the associated volume expansion have the potential to enhance leaching of cations by providing diffusion pathways for cations and water molecules.

Keywords: Molecular dynamics, amorphisation, nuclear waste form, uranium recoil

*Corresponding author. Email: ram.devanathan@pnl.gov

Phone: 509-376-7107 Fax: 509-376-5106 Mailstop: K8-93 


\section{Introduction}

The immobilization of high-level nuclear waste and excess weapons plutonium in a suitable ceramic host material is an urgent concern from the standpoint of environmental protection, national security, and non-proliferation. Due to the anticipated expanded use of nuclear energy to meet growing global energy demand, there is a pressing need to design nuclear waste form materials based on a fundamental understanding of radiation effects in ceramics. Atomistic computer simulation is needed to develop such an understanding; because the small time (ps) and distance $(\mathrm{nm})$ scales of primary radiation damage production in materials preclude direct experimental observation. At the same time, energetic radiation damage processes cannot be simulated by accurate $a b$ initio calculations due to computational limitations. Thus, classical molecular dynamics (MD) simulation using reliable empirical potentials is ideally suited to the task at hand.

This report presents the findings of a classical MD simulation of primary damage state produced in zircon by 10 and $30 \mathrm{keV} \mathrm{U}$ recoils. Zircon is a promising ceramic host material for actinide immobilization, because it is a durable mineral that occurs in nature with up to $5000 \mathrm{ppm} \mathrm{UO}_{2}+$ $\mathrm{ThO}_{2}$, but has been known to occur with total $\mathrm{U}$ and $\mathrm{Th}$ concentrations up to $7 \mathrm{wt} \%$ [1]. is a durable mineral that occurs in nature with $\mathrm{U}$ concentrations as high as $5000 \mathrm{ppm}$. Moreover zircon has been synthesised with 10 wt. \% Pu loading [2]. $\alpha$-decay events in actinide-bearing $\mathrm{ZrSiO}_{4}$ result in a 4-6 $\mathrm{MeV} \alpha$ particle that loses it energy by ionization and isolated defect creation and a $70-100 \mathrm{keV}$ recoil that creates a cascade of atomic displacements leading to amorphization. It is unclear whether amorphization proceeds by accumulation of defects beyond a critical concentration or by direct impact in the cascade. Experimental evidence can be found 
in support of both these models [1]. MD simulation has been used previously to model radiation damage in zircon [3, 4]. Crocombette and Ghaleb [3] observed $\mathrm{Si}$ atoms with the unusual coordination of five oxygen neighbours and $\mathrm{Zr}$ atoms with 6.5 neighbours on average following 4 and $5 \mathrm{keV} \mathrm{U}$ recoils, and concluded that an amorphous core forms in the cascade in zircon. They quantified the extent of the disorder based on the first neighbour environment of the cations and the degree of Si-O-Si polymerisation [3]. Trachenko et al [4] have also observed such polymerisation and local density changes in their study of 30 and $70 \mathrm{keV} \mathrm{Zr}$ cascades in $\mathrm{ZrSiO}_{4}$. However the number and types of defects produced were not analysed in detail. Our previous work with 0.25 to $5 \mathrm{keV}$ recoils of $\mathrm{U}, \mathrm{Zr}, \mathrm{Si}$ and $\mathrm{O}$ in zircon revealed the occurrence of Si-O-Si polymerization even for low energy $(0.25 \mathrm{keV})$ recoils [5].

In the present work, MD simulations of 10 and $30 \mathrm{keV}$ U recoils in $\mathrm{ZrSiO}_{4}$ have been performed with a partial charge model. The main objective of the present work is to understand the primary damage state produced by $\mathrm{U}$ recoils in zircon and the atomistic mechanisms responsible for the amorphization and volume swelling in irradiated zircon. The primary damage state been analyzed in detail using a newly developed criterion for identifying crystalline defects and amorphous regions. In the following sections, the computational methodology is presented and results are discussed in light of experimental observations.

\section{Details of the simulation}

MD simulations of $\mathrm{U}$ recoils in $\mathrm{ZrSiO}_{4}$ were performed using the DLPOLY3 computer code [6]. The interaction between the ions was modelled using a partial charge model [7] developed at CEA Saclay. Since the details of the U-O interaction were not published in the previous work 
[7], we present the details of the potential here. The model consisted of a Coulombic interaction given by

$$
V_{i j}^{C}=\frac{q_{i} q_{j} e^{2}}{4 \pi \varepsilon_{0} r_{i j}}
$$

where $q_{i}$ and $q_{j}$ are the charges of the ions interacting at a distance $r_{i j}, e$ is the electron charge, and $\varepsilon_{0}$ is the vacuum permittivity, and a Born-Mayer interaction at distances less than $10 \AA$ for Zr-O, U-O, Si-O, and O-O pairs given by

$$
V_{i j}^{B}=A_{i j} \exp \left(-\frac{r_{i j}}{\rho_{i j}}\right) .
$$

The parameters $A_{i j}$ and $\rho_{i j}$ for the four interactions mentioned above, and the charges $q$ for the Coulomb potential are given in Table I. The model parameters, including the ion charges, were determined by fitting to the structure, elastic constants and thermodynamic properties of crystalline zircon and coffinite $\left(\mathrm{USiO}_{4}\right)$. This potential was smoothly connected to the repulsive Ziegler-Biersack-Littmark (ZBL) potential [8] at distances much shorter than the equilibrium separation to correctly model energy loss in the cascade. The details of the fit and the ability of our model to reproduce experimentally determined equilibrium properties have been discussed previously [7].

The simulation cell was initially equilibrated at a constant temperature of $30 \mathrm{~K}$ or $300 \mathrm{~K}$ and zero external pressure for $3 \mathrm{ps}$ in the NPT ensemble. The microcanonical ensemble was used for the cascade simulations. The Coulomb term was calculated using smooth particle mesh Ewald 
technique and the velocity Verlet algorithm was used to integrate the equations of motion [6]. A certain kinetic energy was imparted to a $U$ atom with initial velocity along a specific crystallographic direction, and the evolution of the system was followed for about $15 \mathrm{ps}$.

For $10 \mathrm{keV} \mathrm{U}$ recoils, the initial temperature was $30 \mathrm{~K}$ and the box size was about $132 \times 132 \times 134$ $\AA(20 \times 20 \times 22$ unit cells $=211200$ atoms $)$. Three cases were simulated with initial velocities

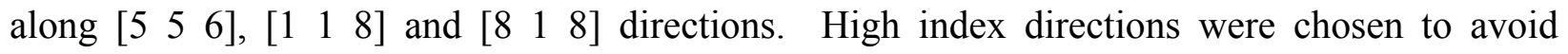
channeling of the recoil. In this case the temperature of the cell rose from $30 \mathrm{~K}$ to a maximum of about $395 \mathrm{~K}$, but settled to a final temperature of about $200 \mathrm{~K}$ after $0.2 \mathrm{ps}$. For comparison, a 30 keV U recoil along [5 5 6] was simulated at $30 \mathrm{~K}$ using a box size $\sim 198 \times 198 \times 201 \AA$ (30x30x33 unit cells $=712800$ atoms). The temperature rose from $30 \mathrm{~K}$ to a maximum of about $350 \mathrm{~K}$ and reached a near constant value of $185 \mathrm{~K}$ after $0.2 \mathrm{ps.} \mathrm{In} \mathrm{addition,} \mathrm{to} \mathrm{examine} \mathrm{the} \mathrm{effect} \mathrm{of}$ temperature a $30 \mathrm{keV} \mathrm{U}$ recoil was simulated at $300 \mathrm{~K}$ along [ 118 118 with a slightly larger box size of $\sim 232 \times 232 \times 232 \AA(35 \times 35 \times 38$ unit cells $=1117200$ atoms $)$. The temperature rose from $300 \mathrm{~K}$ to a maximum of about $500 \mathrm{~K}$ and reached a constant value of about $400 \mathrm{~K}$ within $0.2 \mathrm{ps}$. Energy conservation was excellent and fluctuations in energy were smaller than 1 in $10^{6}$ due to the use of a dynamic variable time step algorithm with a minimum time step of $0.01 \mathrm{fs}$ and a maximum of $1 \mathrm{fs}$.

There are several criteria for the identification of defects in simulated cascades. An atom can be considered a defect if it is displaced more than a certain distance, typically $2 \AA$. However, it is quite possible for the displaced atom to occupy a perfect lattice site at the end of the displacement as in the case of replacement collision sequences. This will result in an 
overestimation of defects. It is also possible for several atoms adjacent to each other to be displaced less than $2 \AA$ each and form an amorphous cluster. In this case an underestimation of defects will result. Criteria based on occupation of Voronoi polyhedra or Wigner cells centered on ideal lattice sites are suitable only for a low concentration of isolated defects. Analysis of our previous work [5] shows that the application of Wigner cell analysis to high energy cascades fails to reveal the existence of amorphous regions, and simplistically identifies defects as vacancies, interstitials and anti-site defects. Thus, the Wigner cell criterion cannot be applied to highly damaged or amorphous regions that are known to be created in collision cascades in zircon $[3,4]$. Topological rules based on connectivity of structural units such as cation coordination polyhedra can be constructed to distinguish between perfect crystalline, defective crystalline, and amorphous regions [9]. The construction of rules for full topological analysis in complex multicomponent ceramics such as zircon is not straightforward.

The present work identifies defective and amorphous regions based on insights from previous simulations of amorphous zircon produced by quenching from the melt [7]. It is known that amorphous zircon is characterized by polymerization of $\mathrm{Si}$ units and reduced $\mathrm{Zr}$ coordination number $(\mathrm{CN})[7,10]$. In this study, criteria based on $\mathrm{Si}$ and $\mathrm{Zr}$ coordination were developed using cut-off distances of 2 and $3 \AA$ for $\mathrm{Si}-\mathrm{O}$ and $\mathrm{Zr}-\mathrm{O}$ bonds, respectively, based on radial distribution functions for crystalline and amorphous $\mathrm{ZrSiO}_{4}$ [7]. A $\mathrm{Zr}$ atom is a defect if it has a $\mathrm{CN}$ less than eight. An $\mathrm{O}$ atom is considered a defect if the number of Si atoms within $2 \AA$ is different from the value of one corresponding to crystalline zircon. If this number is more than one, the $\mathrm{O}$ atom becomes a bridge between two $\mathrm{Si}$ atoms. Defects on the $\mathrm{Si}$ sublattice are connected to other Si atoms via O bridges. To identify amorphous regions neighbors within $3 \AA$ 
of the defects discussed above were considered. A defect is considered an amorphous atom if more than half of its neighbors are also defects. By this criterion, the set of amorphous atoms is a subset of the set of defects. The region within the $3 \AA$ radius typically contains about 10 atoms, which means that an amorphous atom is a defect surrounded by at least 6 other defects.

\section{Results and discussion}

Fig. 1 shows the displacement of three $10 \mathrm{keV}$ U primary knock-on atoms (PKAs) from the starting point on the $\mathrm{Zr}$ sublattice. The cascades were initiated from different positions for these three cases. A logarithmic time scale is employed to show the changes over three orders of magnitude from 10 fs to 10 ps. The PKA comes to its resting position within 1 ps after displacements of 71, 61 and $74 \AA$, respectively for initial velocity along [5 5 6 6], [ $\left.\begin{array}{lll}1 & 1 & 8\end{array}\right]$ and [8 1 8] directions. For the corresponding $30 \mathrm{keV}$ cascade along [5 5 6] at the same temperature of 30 $\mathrm{K}$, the PKA displacement was $108 \AA$ and the PKA attained it within 1 ps. Despite the differences in crystallographic direction, the displacements of the three $10 \mathrm{keV}$ PKAs nearly fall on the same line up to $0.2 \mathrm{ps}$, which indicates that the ballistic phase is very similar regardless of PKA direction.

A similar conclusion can be reached from Fig. 2, which shows the number of energetic atoms with kinetic energy in excess of $1 \mathrm{eV}$ as a function of time for the three $10 \mathrm{keV} \mathrm{U}$ PKAs

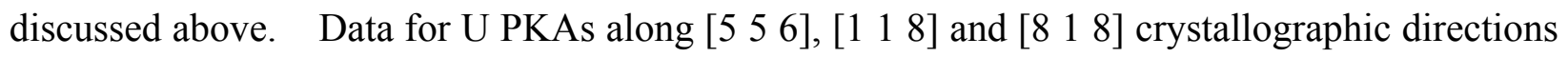
are indicated by circles, squares and triangles, respectively. The data seems to follow the same curve up to $10 \mathrm{ps}$. From 0.02 to $0.15 \mathrm{ps}$, the number of energetic atoms rises sharply as the $\mathrm{U}$ recoil transfers its energy to lattice atoms. Subsequently, these atoms lose their energy through 
heat transfer and defect creation. After about 5 ps, none of the atoms have kinetic energy in excess of $1 \mathrm{eV}$. From the temperature rise of the simulation cell, it was estimated that half of the initial energy was expended in creating defects, and the remaining half was dissipated as heat. The number of amorphous atoms is also plotted in Fig. 1 as solid, dashed and dash-dotted lines

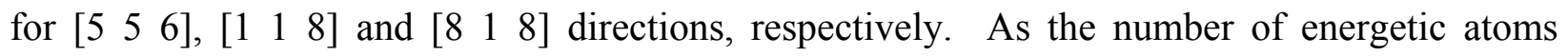
decreases due to energy transfer to the lattice, the number of amorphous atoms rises and attains a nearly constant value by 3 ps. Similar behaviour was observed for $30 \mathrm{keV} \mathrm{U}$ recoils.

The ratio of amorphous atoms to the total number of defects is an important characteristic of the primary damage state. It has important implications for defect recovery under dynamic and thermal annealing, and radiation resistance. If this ratio is close to zero, the damage will consist mainly of isolated defects as in the case of silicon carbide - a highly radiation resistant ceramic [11]. This parameter has not been systematically examined in previous radiation damage simulations in ceramics. Fig. 3 shows the fraction of defects created by $10 \mathrm{keV}$ U recoils in $\mathrm{ZrSiO}_{4}$ that are amorphous based on the criterion discussed in the previous section. Once again, the curves for the three cascades nearly coincide. A large fraction of the defects $(0.46-0.50)$ produced in the cascade are amorphous. The total number of amorphous and defective atoms in

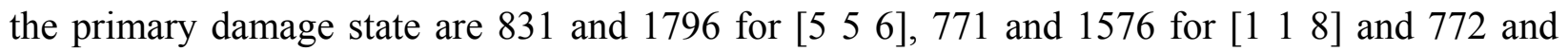
1681 for [8 18], respectively. Let us estimate the maximum possible value for the amorphous fraction in the present case. If the approximately 1600 defects produced in the cascade were all contained in a sphere with the density of zircon, the sphere would have a radius of $16 \AA$. Assuming that a $2 \AA$ layer on the surface is occupied by defects and the interior is amorphous, one would obtain $(14 / 16)^{3}$ or 0.67 for the theoretical maximum amorphous fraction. The fact 
that the amorphous fraction is close to this value indicates that direct impact amorphization is very effective in cascades produced by heavy recoils in zircon.

Fig. 4(a) is a perspective projection of the defects produced by a $10 \mathrm{keV}$ U PKA along [5 5 6] (from bottom right to top left) in zircon at $30 \mathrm{~K}$. The colors green, blue and red are used to represent $\mathrm{Zr}$, Si and $\mathrm{O}$ respectively throughout the electronic version of the present report. A dense amorphous core elongated along the direction of travel of the PKA is produced. The core can be seen in Fig. 4(b), which is in a similar orientation to Fig. 4(a), but only the amorphous atoms are represented. A small amorphous cluster is present near the main amorphous core. Unlike a typical subcascade that resembles a tree branch, this small cluster is not connected to the main amorphous core, which indicates effective energy transfer through replacement collision sequences. The difference between Figs. 4(a0 and 4(b) is accounted by the defects (50$54 \%$ of the total) situated at the periphery of the amorphous core in analogy to the sphere example discussed above. For comparison, Figs. 5(a) and 5(b), respectively, show the defects and amorphous core produced by a $30 \mathrm{keV} \mathrm{U}$ PKA along [5 5 6] at $30 \mathrm{~K}$. At this higher energy, many more small amorphous clusters are produced, and are well separated from each other and the central amorphous core. Some are enriched in $\mathrm{Zr}$ while others in $\mathrm{Si}$ relative to zircon stoichiometry. The number of amorphous atoms and defects was 2550 and 5266, respectively, for an amorphous fraction of 0.48 in agreement with the $10 \mathrm{keV}$ PKA results. However, at 300 $\mathrm{K}$ the corresponding numbers for a $30 \mathrm{keV}$ U PKA were 2401, 6555 and 0.37, respectively. Fig. 6 shows the defects produced by this PKA. In addition to the main cascade core and small clusters surrounding it, a number of isolated oxygen defects are observed at the periphery of the damage. It is unclear if this occurrence of isolated oxygen defects and the resulting lower value 
of the amorphous fraction is a statistical effect or a temperature effect. Detailed statistical studies of cascades in zircon at different temperatures and PKA energies are needed to completely characterize the observed amorphous clusters and get better insights into changes in the amorphous fraction with PKA energy.

This discovery of small amorphous cluster formation adds to our understanding of the primary damage state in zircon. Recently, Trachenko et al [13] have discussed the percolation of disordered regions leading to amorphization of the material. The present results show that the primary damage state in zircon can be quite complex and consist of spatially separated multiple disordered regions that differ in size and chemistry, as opposed to the traditional picture of a single amorphous core. This complexity must be taken into account in macroscopic models of damage accumulation. Moreover, at elevated temperatures, these chemically inhomogeneous clusters could play a role in nucleating nanocrystals of zirconia. The formation of randomly oriented nanocrystals of tetragonal $\mathrm{ZrO}_{2}$ in an amorphous $\mathrm{SiO}_{2}$ matrix has been observed during irradiation of $\mathrm{ZrSiO}_{4}$ at $1050 \mathrm{~K}$ [14].

In an effort to understand the structural features of the primary damage the average $\mathrm{Zr} \mathrm{CN}$ and the degree of Si-O-Si polymerization were determined. The evolution of $\mathrm{Zr}$ defect $\mathrm{CN}$ for 10 keV U PKA, shown in Fig. 7, indicates that Zr defects are severely undercoordinated even in the ballistic phase of the cascade. The average $\mathrm{Zr} \mathrm{CN}$ attains a steady value of 6.4 after $0.2 \mathrm{ps}$ with fluctuations of about \pm 0.1 . The final value of $\mathrm{Zr} \mathrm{CN}$ was found to be 6.3 for the two $30 \mathrm{keV} \mathrm{U}$ cascades with similar fluctuations. This value is in excellent agreement with recent extended Xray absorption fine structure experiments that show that $\mathrm{Zr}$ in nuclear waste glasses has a 
coordination number of 6.3 [15]. The degree of polymerization of $\mathrm{Si}, Q$, is shown in Fig. 8 for $10 \mathrm{keV} \mathrm{U}$ PKA. $Q$ is the average number of bridging oxygen per Si defect. In perfect crystal zircon, $\mathrm{Si}$ is not polymerized and so $Q$ is zero. $Q$ increases from about 1.2 at $0.15 \mathrm{ps}$, when amorphization begins (see Fig. 2) and reaches a final value of 1.5 to 1.6 at about 3 ps, when the number of amorphous atoms becomes fairly constant. The final $Q$ values were 1.5 and 1.4 for 30 $\mathrm{keV} \mathrm{U}$ PKA at 30 and $300 \mathrm{~K}$, respectively. The distribution of bridging oxygen is shown in Fig. 9 for 10 and $30 \mathrm{keV} \mathrm{U}$ PKA along [ 556 ] at $30 \mathrm{~K}$ and is nearly identical for the two cases. Thus the first neighbor environment of $\mathrm{Zr}$ and $\mathrm{Si}$ defects is quite similar for all 5 cascades simulated.

In an effort to analyse the composition of the amorphous and peripheral defect regions, the relative proportions of $\mathrm{Zr}, \mathrm{Si}$, and $\mathrm{O}$ among defects and amorphous atoms in $10 \mathrm{keV} \mathrm{U}$ cascades were determined and are shown in Figs. 10 and 11, respectively. Circles, squares and triangles

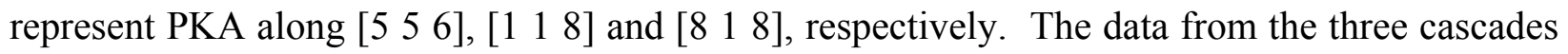
lie on top of each other, which shows that this is a characteristic feature of cascades in zircon. Fig. 10 reveals that $\mathrm{O}$ defects are the most numerous and account for $52-54 \%, \mathrm{Zr}$ defects are next at $25-26 \%$ and Si defects constitute $21-22 \%$.. The defect percentages for $30 \mathrm{keV} \mathrm{U}$ cascades are 53-60\% O, 24-26\% $\mathrm{Zr}$, and $16-21 \% \mathrm{Si}$ defects. The proportions of $\mathrm{Zr}$ and $\mathrm{Si}$ are slightly different in the amorphous state with Si being more numerous than $\mathrm{Zr}$ as plotted in Fig. 11. Amorphous atoms are constituted by $55-57 \%$ O, 24-26\% Si and $18-19 \% \mathrm{Zr}$. This indicates that the amorphous zones are relatively enriched in $\mathrm{Si}$, while the perclearly ipheral defects are richer in Zr. As discussed by Crocombette and Ghaleb [3], such segregation across the damage zone may be a key factor in the experimentally observed nucleation of $\mathrm{ZrO}_{2}$ nanocrystals in zircon irradiated at elevated temperatures [14]. 
The present simulations have shown that there are fundamental features that are common to heavy-ion recoil cascades in zircon regardless of PKA energy or direction. The $\mathrm{Zr}$ defect coordination number of about 6.3 suggests that $\mathrm{Zr}$ defects are surrounded by six or seven $\mathrm{O}$. Si is polymerized and the average $Q$ value is about 1.5 , which is smaller than the average of 2 observed in our simulations of amorphous zircon [7]. A large volume expansion is needed to accommodate this severe $\mathrm{Zr}$ undercoordination and $\mathrm{Si}$ polymerization, because the bond distances are not significantly changes as revealed in our previous study of disordered zircon [7]. Experimental studies [1 and references therein] have shown that the volume expansion associated with amorphization of zircon can be as high as $18 \%$. Such a large volume expansion can create easy migration pathways for water and cations and enhance leaching of cations upon disordering of zircon by radiation. The observation of spatially separated amorphous clusters in the primary damage state, extraction of insights about chemical segregation and the quantification of the amorphous fraction in the primary damage state are key contributions of the present work.

\section{Conclusions}

We have used MD simulations with a partial charge model and a massively parallel computer code to model 10 and $30 \mathrm{keV}$ recoil damage in zircon at 30 and $300 \mathrm{~K}$. Direct impact amorphization occurs in the cascade. Nearly half of the defects produced are in an amorphous core or amorphous clusters. The remaining defects are at the boundary between amorphous and crystalline regions. Chemical inhomogeneity of amorphous clusters and composition differences 
between the cascade core and periphery could play an important role in nanoscale segregation of zircon irradiated at elevated temperatures.

\section{Acknowledgements}

This research was supported by the Division of Materials Sciences and Engineering, Office of Basic Energy Sciences, U.S. Department of Energy under Contract DE-AC05-76RL01830. This research was performed in part using the MSCF in EMSL, a national scientific user facility sponsored by the U.S. DOE, OBER and located at PNNL, and used resources of the National Energy Research Scientific Computing Center, which is supported by the Office of Science of the U.S. Department of Energy under Contract No. DE-AC03-76SF00098.

\section{References}

[1] C. S. Palenik, L. Nasdala, R. C. Ewing. Radiation damage in zircon. Amer. Mineralog., 88, 770 (2003).

[2] W. J. Weber. Radiation-induced defects and amorphization in zircon. J. Mater. Res., 5, 2687 (1990).

[3] J.-P. Crocombette, D. Ghaleb. Molecular dynamics modeling of irradiation damage in pure and uranium-doped zircon. J. Nucl. Mater., 295, 167 (2001).

[4] K. O. Trachenko, M. T. Dove, E. K. H. Salje. Structural changes in zircon under $\alpha$-decay irradiation. Phys. Rev. B, 65, 180102 (2002).

[5] R. Devanathan, L. R. Corrales, W. J. Weber, A. Chartier, C. Meis. Molecular dynamics simulation of defect production in collision cascades in zircon. Nucl. Instrum. and Meth. B 228, 299 (2003). 
[6] I. T. Todorov, W. Smith, K. Trachenko, M. T. Dove. DL_POLY_3: new dimensions in molecular dynamics simulations via massive parallelism. J. Mater. Chem., 16, 1911 (2006).

[7] R. Devanathan, L. R. Corrales, W. J. Weber, A. Chartier, C. Meis. Molecular dynamics simulation of disordered zircon. Phys. Rev. B 69, 064115 (2004).

[8] J. F. Ziegler, J. P. Biersack, U. Littmark. The stopping and range of ions in matter, Pergamon, New York (1985).

[9] X. L. Yuan, L. W. Hobbs. Modeling chemical and topological disorder in irradiationamorphized silicon carbide. Nucl. Instrum. and Meth. B, 191, 74 (2002).

[10] E. Balan, F. Mauri, C. J. Pickard, I. Farnan, G. Calas. The aperiodic states of zircon: an ab initio molecular dynamics study. Amer. Mineralog., 88, 1769 (2003).

[11] R. Devanathan, W. J. Weber, F. Gao. Atomic scale simulation of defect production in irradiated 3C-SiC. J. Appl. Phys., 90, 2303 (2001).

[12] W. J. Weber, R. C. Ewing, L. M. Wang. The radiation-induced crystalline-to-amorphous transition in zircon. J. Mater. Res., 9, 688 (1994).

[13] K. Trachenko, M. T. Dove, T. Geisler, I. Todorov, W. Smith. J. Phys.: Condens. Matter, 16, S2623 (2004).

[14] A. Meldrum, S. J. Zinkle, L. A. Boatner, R. C. Ewing. Heavy-ion irradiation effects in the $\mathrm{ABO}_{4}$ orthosilicates: Decomposition, amorphization and recrystallization. Phys. Rev. B, 59, 3981 (1999).

[15] L. Galoisy, E.Pelgrin, M. A. Arrio, P. Ildefonse, G. Calas, D. Ghaleb, C. Fillet, F. Pacaud. Evidence for 6-coordinated $\mathrm{Zr}$ in inactive nuclear waste glasses. J. Amer. Ceram. Soc., 82, 2219 (199). 
TABLE I. Potential parameters for $(\mathrm{UZr}) \mathrm{SiO}_{4}$

\begin{tabular}{lccc}
\hline \hline Ions & $A_{i j}(\mathrm{eV})$ & $\rho_{i j}(\AA)$ & Charges \\
\hline Zr-O & 1967.0 & 0.305004 & $\mathrm{Zr}:+3.8$ \\
$\mathrm{U}-\mathrm{O}$ & 5424.8 & 0.281723 & $\mathrm{U}:+3.8$ \\
Si-O & 1277.0 & 0.227225 & $\mathrm{Si}:+2.0$ \\
$\mathrm{O}-\mathrm{O}$ & 1755.0 & 0.306820 & $\mathrm{O}:-1.45$ \\
\hline \hline
\end{tabular}




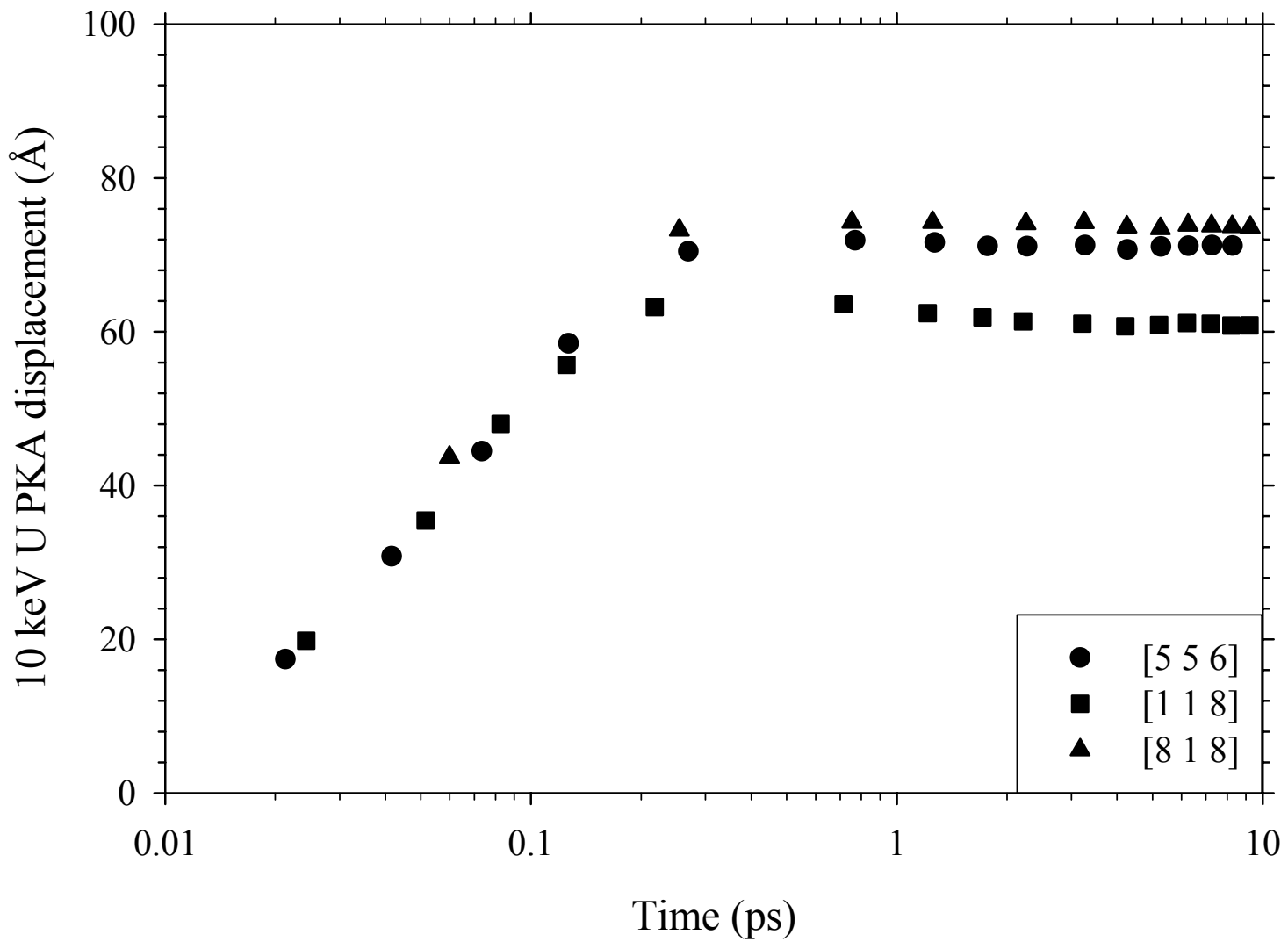

Fig. 1. R. Devanathan et al. 


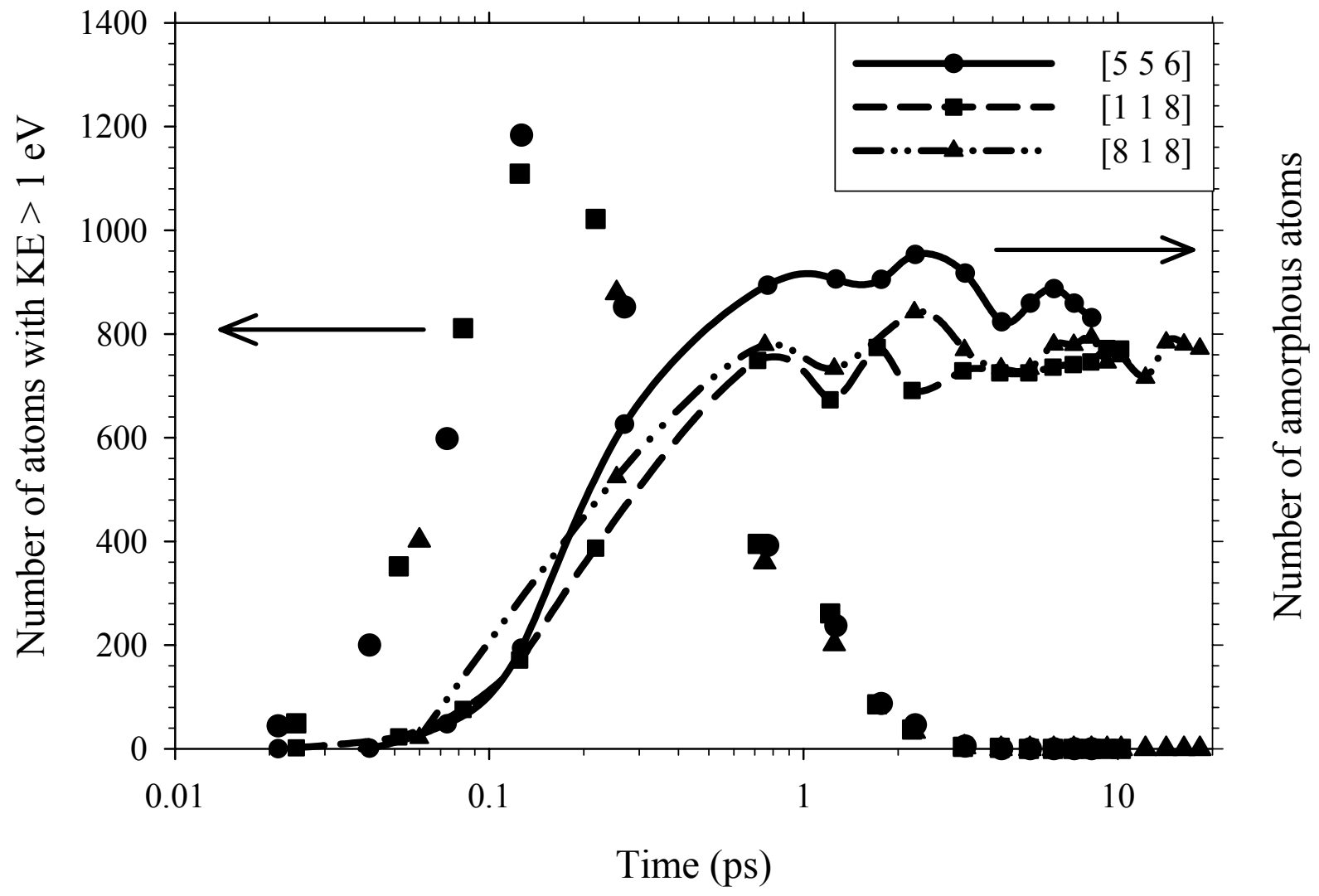

Fig. 2. R. Devanathan et al. 


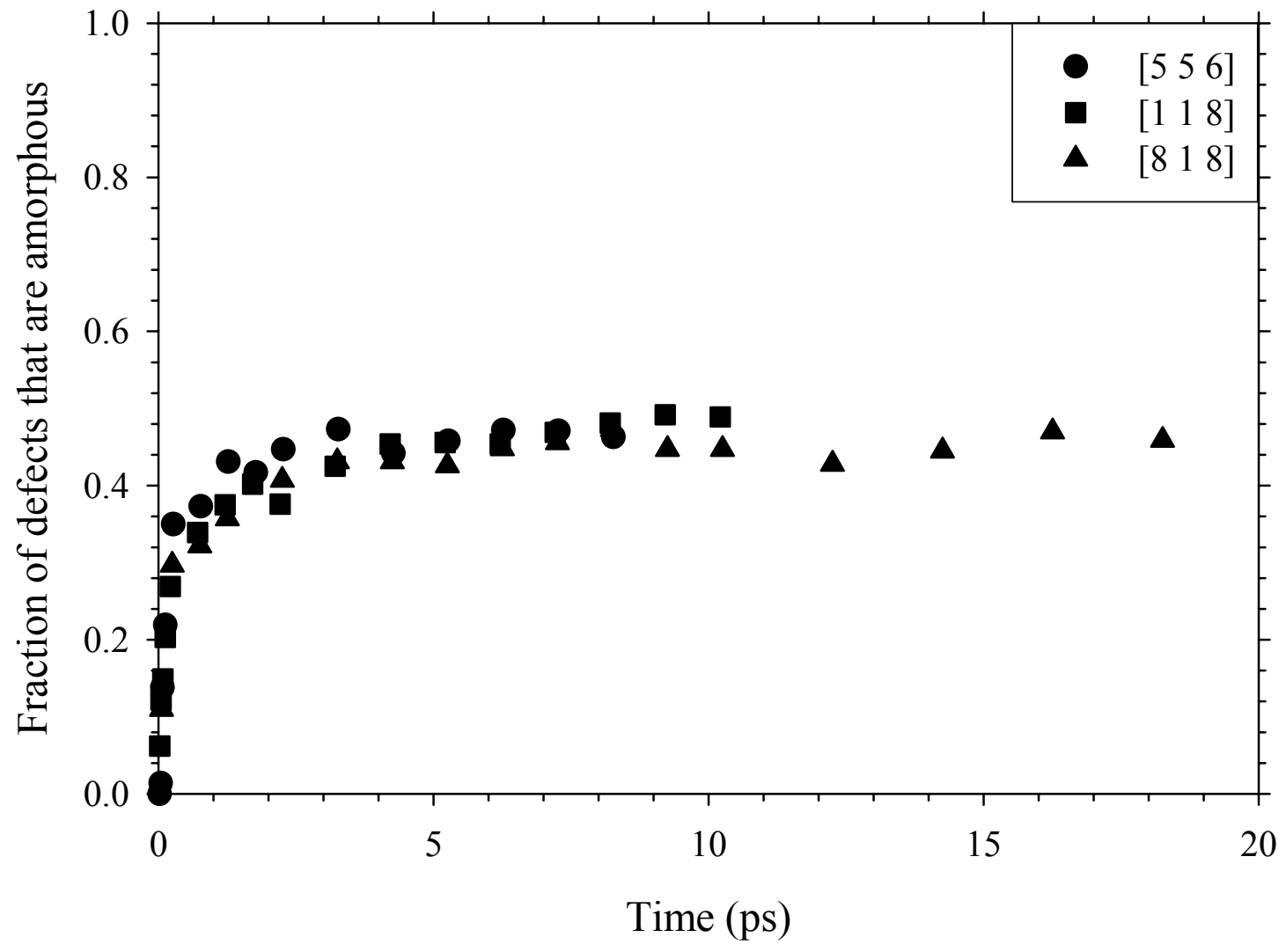

Fig. 3. R. Devanathan et al. 


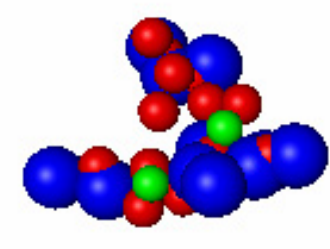

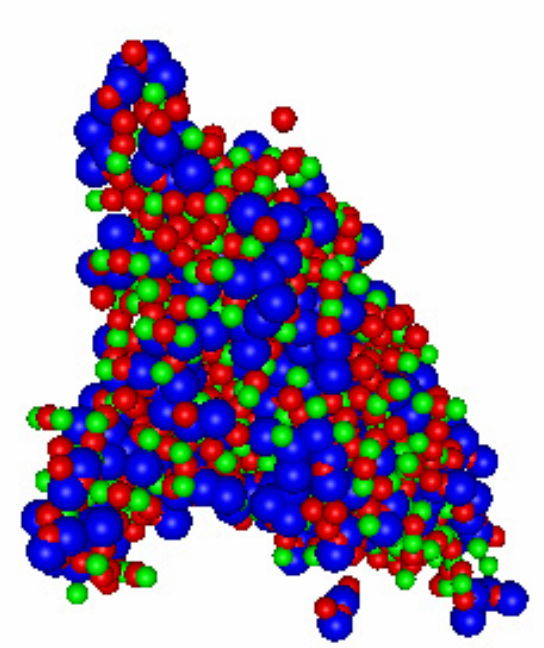

a)

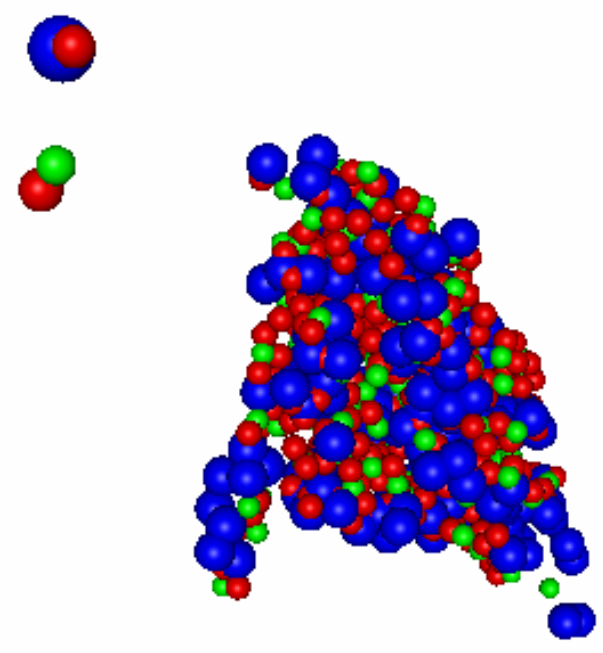

b)

Fig. 4. R. Devanathan et al. 

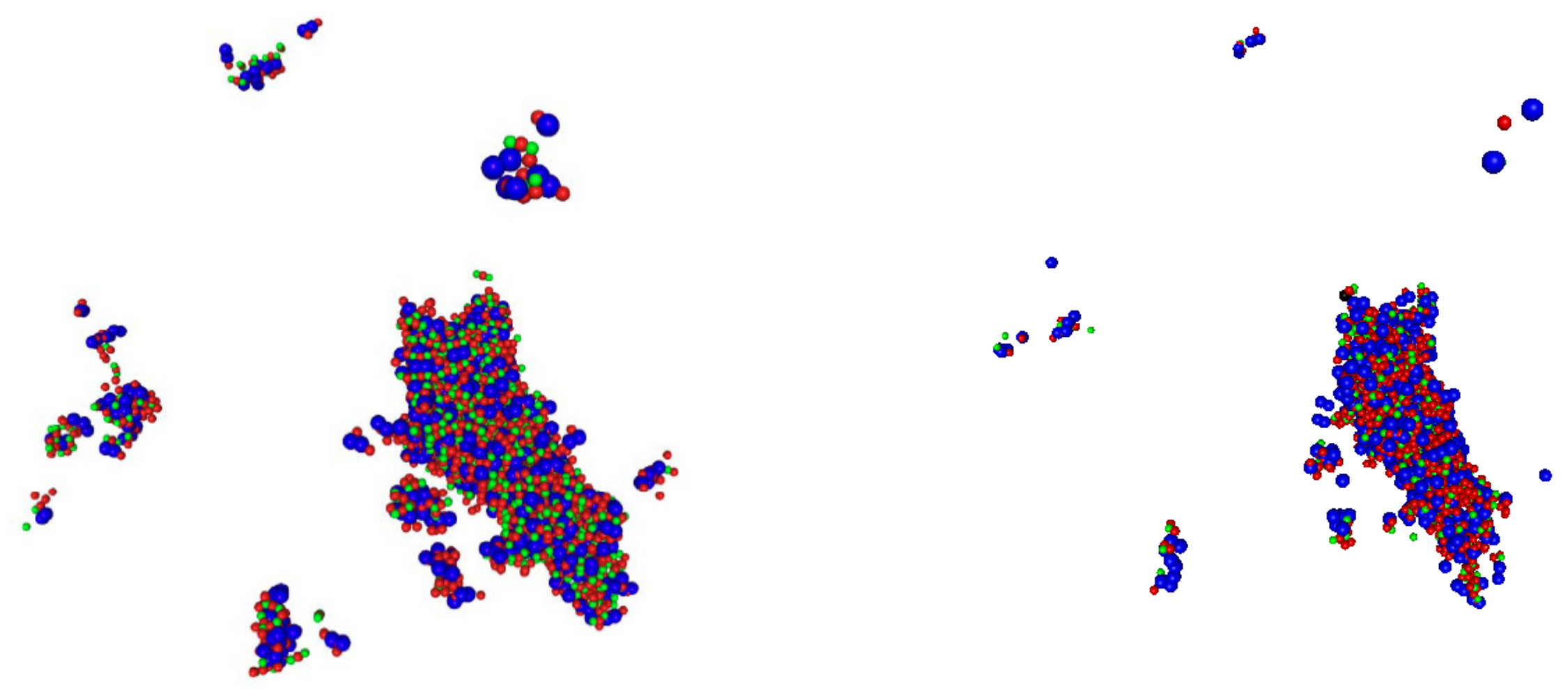

Fig. 5. R. Devanathan et al. 


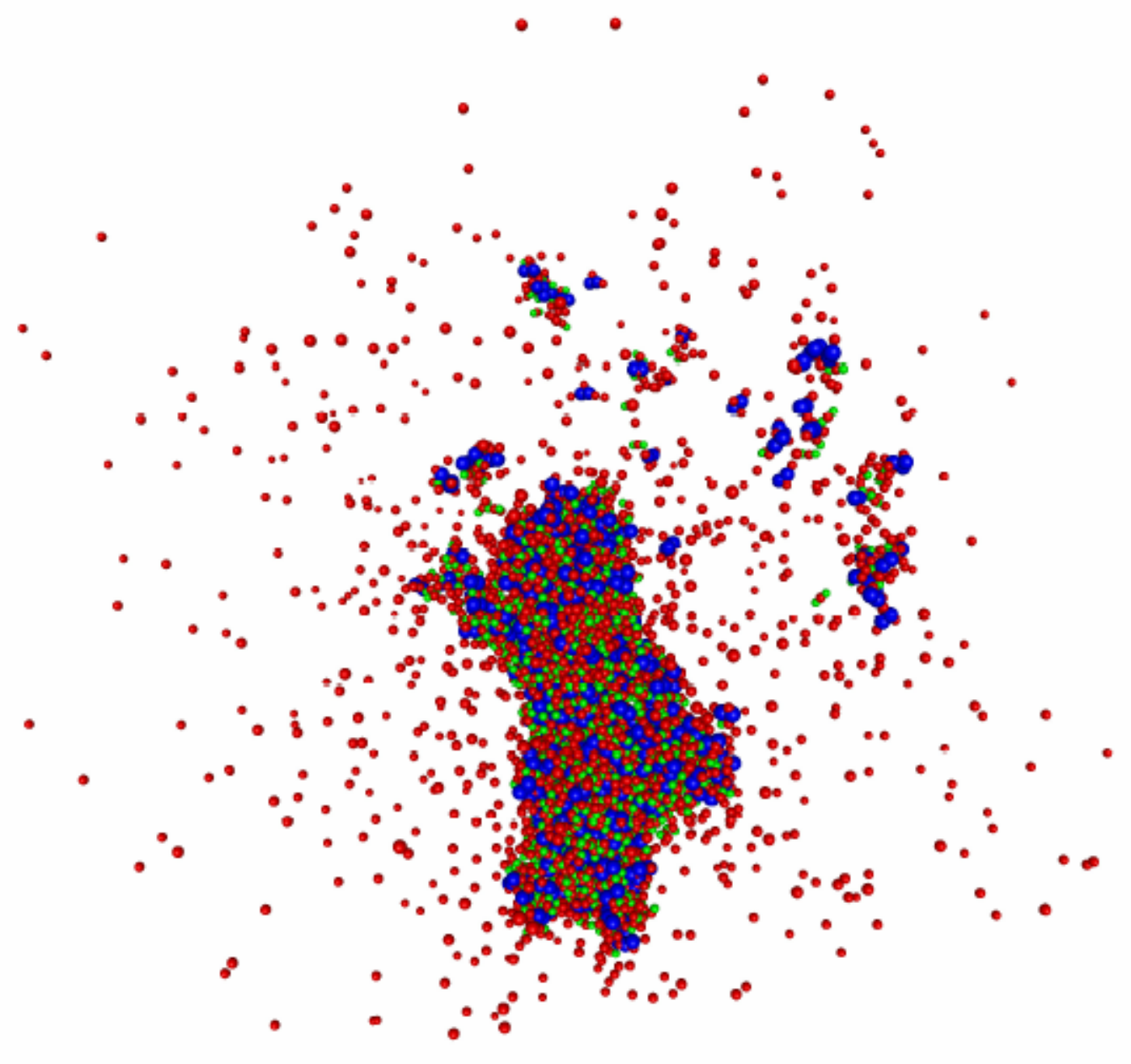

Fig. 6. R. Devanathan et al. 


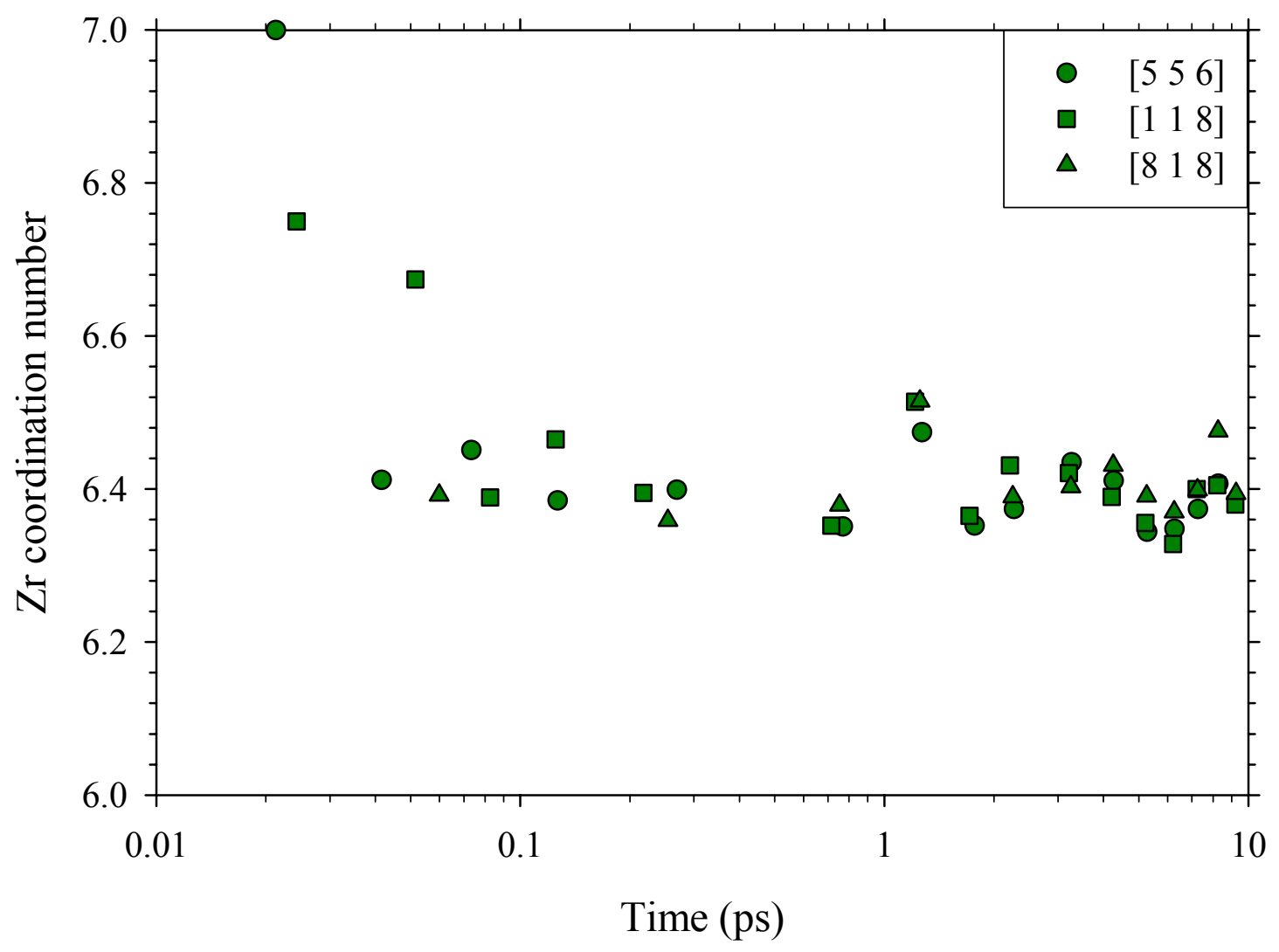

Fig. 7. R. Devanathan et al. 


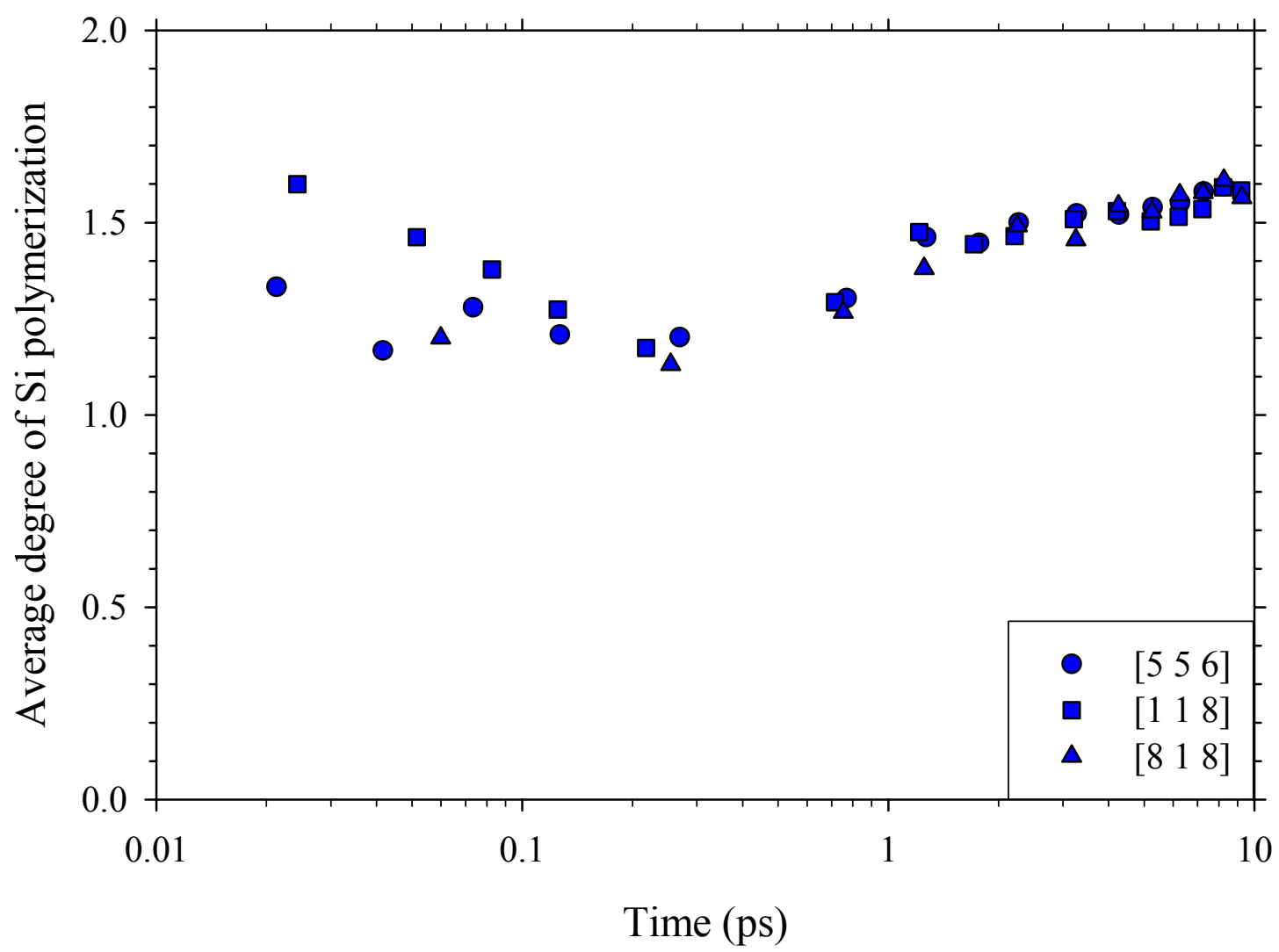

Fig. 8. R. Devanathan et al. 


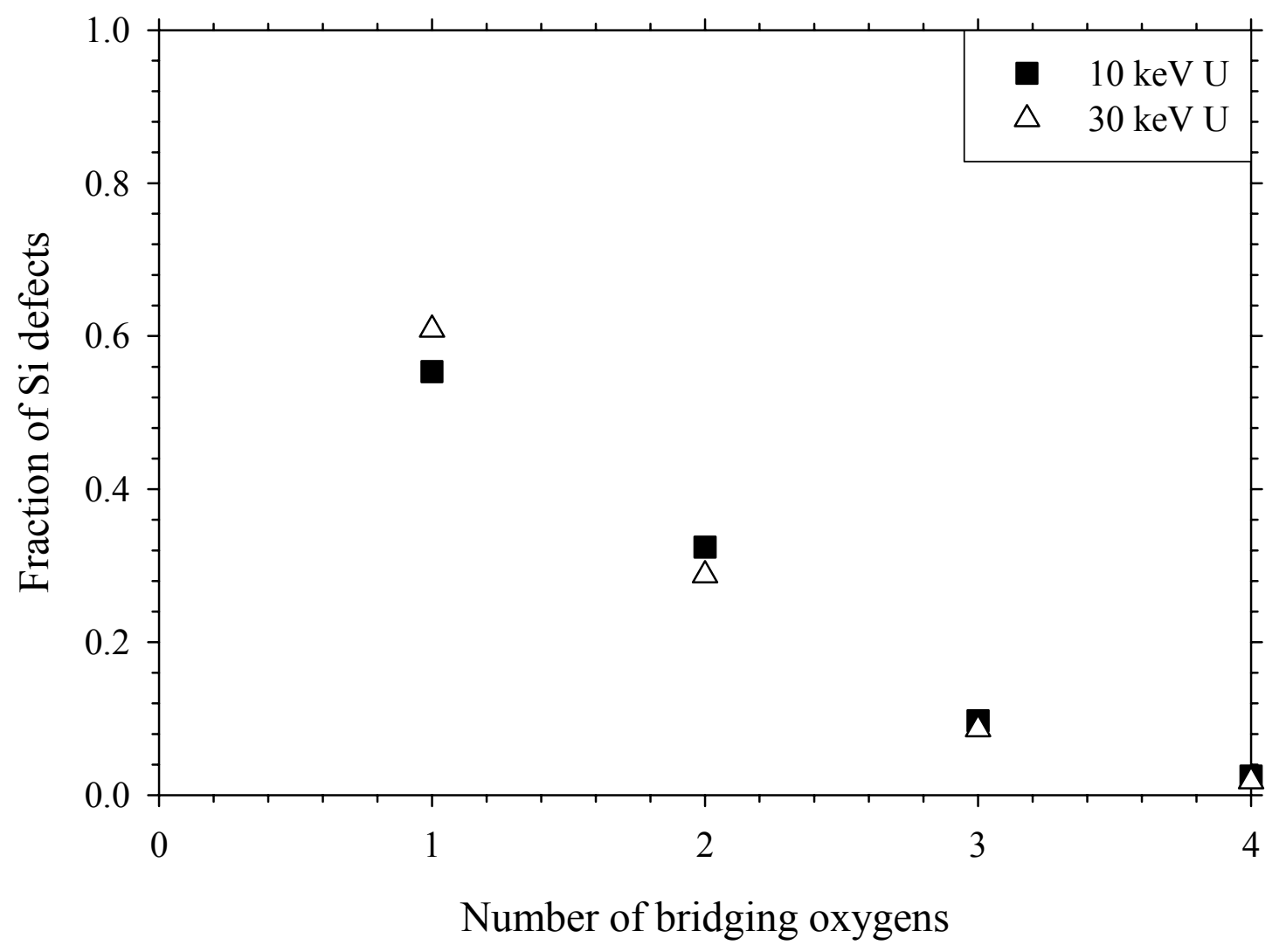

Fig. 9. R. Devanathan et al. 


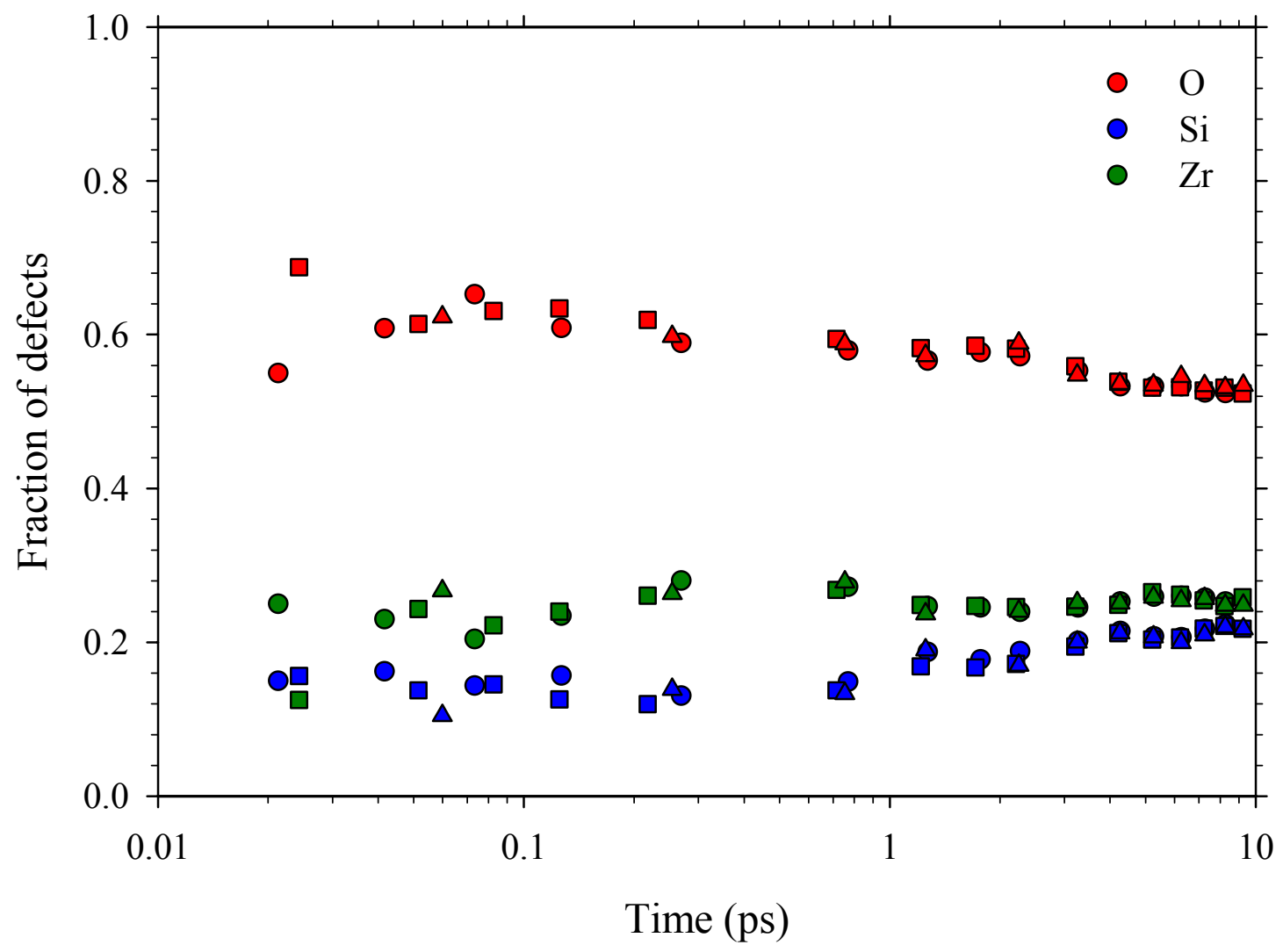

Fig. 10. R. Devanathan et al. 


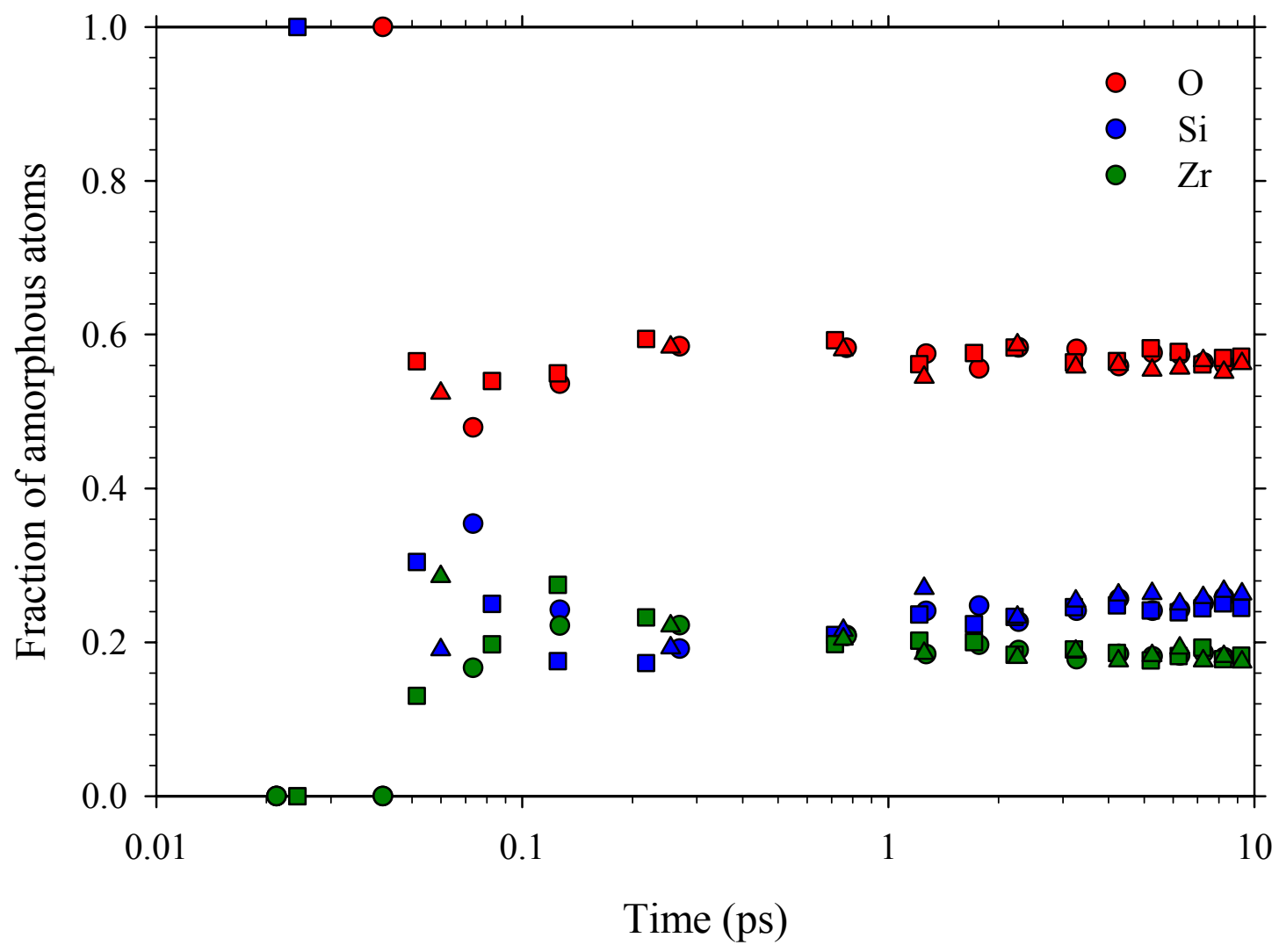

Fig. 11. R. Devanathan et al. 